\title{
Outcome of ICG-assisted ILM peel in macular hole surgery
}

Abstract

Purpose To investigate whether indocyanine green (ICG) staining of the internal limiting membrane (ILM) improves surgical outcome. Methods A total of 34 patients were identified who underwent macular hole surgery with ILM peeling augmented with ICG. These were matched retrospectively with 34 patients who underwent macular hole surgery without the use of ICG. Closure rates from primary and secondary procedures were compared, as were changes in Snellen and Logmar visual acuity. Results There was no significant difference between the two groups with reference to demographic features of age, sex, staging of the macular holes, and the proportion subsequently undergoing cataract surgery. The mean follow-up period was 7.7 months in the ICG group and 6.3 months in the non-ICG group. Closure rates from primary surgery were $91.2 \%$ in the ICG group and $73.5 \%$ in the non-ICG group $(P=0.056)$, whereas overall closure rates following further surgery were similar in both groups $\mathbf{( 9 4 . 1}$ and $\mathbf{9 1 . 2 \%}$, respectively). Logmar visual improvement above baseline was achieved in $53 \%$ of the non-ICG group compared to $82 \%$ of the ICG group $(P=0.01)$. Where primary hole closure occurred, there was no statistically significant difference in visual outcome between the two groups.

Conclusion ICG-assisted ILM peel in macular hole surgery is associated with a higher closure rate following a single surgical procedure. This difference was found to approach statistical significance $(P=\mathbf{0 . 0 5 6})$. Overall visual improvement was greater in the ICG group ( $P=0.01)$; however, this reflected the higher closure rates. Visual outcomes between the two groups were comparable where primary hole closure occurred. Eye (2004) 18, 804-808. doi:10.1038/sj.eye.6701328 Published online 30 January 2004
J Lochhead, E Jones, D Chui, S Lake, N Karia, CK Patel and P Rosen

Keywords: ICG; macular hole; ILM

\section{Introduction}

Macular hole was first described by Gass, ${ }^{1,2}$ and is characterised by an anatomical opening or dehiscence in the fovea. The mechanism is uncertain, but is believed to involve tangential or anterior/posterior vitreofoveal traction. The four stages of macular hole formation are stage $1 \mathrm{~A}$, flattening of the umbo with loss of foveal depression and a yellow macular spot, stage 1B, loss of the foveal depression with a yellow macular ring, stage 2, a small full thickness retinal hole inside the yellow ring, stage 3, $d<400 \mu \mathrm{m}$ hole without separation of the posterior hyaloid face from the macular, stage $4, d>400 \mu \mathrm{m}$ hole with separation of the posterior hyaloid from the macular and optic disc. Macular holes at stage 3 or 4 are typically associated with poor acuity and symptoms of distortion that rarely improve spontaneously.

Vitrectomy to close macular holes was first described in $1991 .^{3}$ The benefits of surgery for stages 2-4 macular holes have been demonstrated. ${ }^{4,5}$ Closure rates vary between 60 and $100 \%$ in reported series, and it has been shown that with ILM peeling the rates of anatomical closure are greater and late reopening reduced. ${ }^{6-11}$

Visualisation of the internal limiting membrane (ILM) is difficult and failure to successfully remove the ILM may contribute to failure in hole closure. Indocyanine green (ICG) is used as an adjunct to the surgery enabling visualisation of the ILM. ${ }^{12,13}$ Whether ICG toxicity is clinically significant is controversial. Our study attempts to address this issue using a case-control analysis of macular hole surgery at a UK-based teaching hospital. 


\section{Methods}

In total, 34 consecutive patients were identified with stage 3 and 4 macular holes of less than 12 months duration, who underwent macular hole surgery with ILM peel augmented with ICG. These were matched retrospectively with 34 patients who underwent macular hole surgery and ILM peel without the use of ICG. Closure rates from primary and secondary procedures were compared as were changes in Snellen and Logmar visual acuity.

All surgery was performed by surgeons with at least 12 months experience in vitreoretinal surgery (PR, CKP, DC, $\mathrm{NK}$ ), each having performed a minimum of 300 vitrectomy procedures. This included a standard threeport pars plana vitrectomy with removal of the posterior hyaloid. ICG was diluted to $5 \mathrm{mg} / \mathrm{ml}$ concentration using balanced salt solution (BSS) and a small volume (approximately $0.1 \mathrm{ml}$ ) was injected over the macular, inside the macular arcades. The eye remained fluid filled at this stage, but the continuous infusion of BSS was temporarily halted. The ICG was then removed after a contact time of just $10 \mathrm{~s}$. At this concentration, the ILM staining was consistently intense and uniform. ILM peel was undertaken with a microvitreoretinal blade to initiate the flap and intraocular forceps to peel the ILM in a circular fashion around the macular hole. At the end of surgery, $14 \% \mathrm{C}_{3} \mathrm{~F}_{8}$ gas was used to provide tamponade. The patients were instructed to posture for $75-80 \%$ of the time over a 2-week period.

The staging of the macular holes was confirmed intraoperatively. The anatomical end points of the macular hole surgery were categorized as 'elevated/ open', 'flat/open' and 'flat/closed' ${ }^{14}$ Those classified as 'flat/open' and 'flat/closed' were considered 'closed' in this study. Primary hole closure was also studied as a means of comparing visual outcomes between the two groups without the introduction of confounding factors such as phototoxicity that may accompany multiple procedures.

Statistical analysis of the data was performed using $\chi^{2}$, Fisher's exact and student's $t$-test.

\section{Results}

There were no significant differences between the two groups with reference to demographic features of age $(P=0.13)$, sex $(P=1.0)$, staging of the macular holes $(P=1.0)$ and the proportion subsequently undergoing cataract surgery $(P=1.0)$ (Table 1$)$. The mean follow-up period was 7.7 months (CI 95\% 1.5) in the ICG group and 6.3 months (CI 95\% 2.7) in the non-ICG group. Closure rates from primary surgery were $91.2 \%$ in the ICG group and $73.5 \%$ in the non-ICG group $(P=0.056)$, whereas
Table 1 Demographic data and outcomes for all 68 cases studied

\begin{tabular}{lccc}
\hline & Non-ICG & ICG & P-value \\
\hline Number & 34 & 34 & \\
Male & 10 & 10 & \\
Female & 24 & 24 & \\
Age & 67.5 & 69.9 & $P=0.13$ \\
& & & \\
Stage 3 & $27(79.4 \%)$ & $27(79.4 \%)$ & \\
Stage 4 & $7(20.6 \%)$ & $7(20.6 \%)$ & \\
F/U period & 6.3 months & 7.6 months & \\
Pseudophakic at & $12(35.3 \%)$ & $13(38.2 \%)$ & \\
final F/U & & & \\
Residual significant & $5(14.7 \%)$ & $10(29.4 \%)$ & \\
LO & & & \\
Preop VA $\geq 6 / 24$ & $11(32.4 \%)$ & $10(29.4 \%)$ & \\
Preop VA <6/60 & $8(23.5 \%)$ & $8(23.5 \%)$ & \\
& & & \\
Number of ops & 41 & 36 & \\
Primary closure & $25(73.5 \%)$ & $31(91.2 \%)$ & $P=0.056$ \\
Secondary closure & $6 / 7$ & $1 / 2$ & \\
Overall closure & $31(91.2 \%)$ & $32(94.1 \%)$ & \\
& & & \\
Snellen line change & 1.00 & 1.21 & $P=0.62$ \\
$\geq 2$ Snellen line & $13(38.2 \%)$ & $13(38.2 \%)$ & \\
improvement & & & \\
Postop VA $\geq 6 / 24$ & $18(52.9 \%)$ & $20(58.8 \%)$ & \\
Postop VA <6/60 & $4(11.8 \%)$ & $1(2.9 \%)$ & \\
\hline
\end{tabular}

overall closure rates following further surgery were similar in both groups (94.1 and 91.2\%, respectively).

Logmar visual improvement above baseline occurred in 18 patients $(53 \%)$ in the non-ICG group (Figure 1) compared to 28 patients (82\%) in the ICG group (Figure 2) $(P=0.01)$. Amongst those patients where primary hole closure occurred, this difference narrowed to 20/25 patients $(80 \%)$ in the non-ICG group compared to $27 / 31$ patients $(87 \%)$ in the ICG group. This difference did not achieve statistical significance $(P=0.5)$. At the end of the follow-up period, both groups contained five patients with a final reduction in VA (Figures 1 and 2) resulting from secondary lens opacity. In addition, the non-ICG group contained one patient with an epiretinal membrane, one patient with cystoid macular oedema, and a single patient with untreated posterior capsular opacification, all causing a reduction in VA.

The mean Snellen line change was +1.21 (CI 95\% 0.5) in the ICG group and +1.00 (CI 95\% 0.8) in the non-ICG group. Where primary hole closure occurred, there was a significant improvement in Logmar VA in both groups, 0.38 in the ICG group $(P<0.001)$ and 0.45 in the non-ICG group $(P<0.005)$ (Table 2$)$. These differences in visual outcome between the groups were not statistically significant $(P=0.64$ and 0.46$)$. Amongst those patients with primary hole closure, the mean Snellen line change 
Non-ICG Logmar Visual acuities (VA)

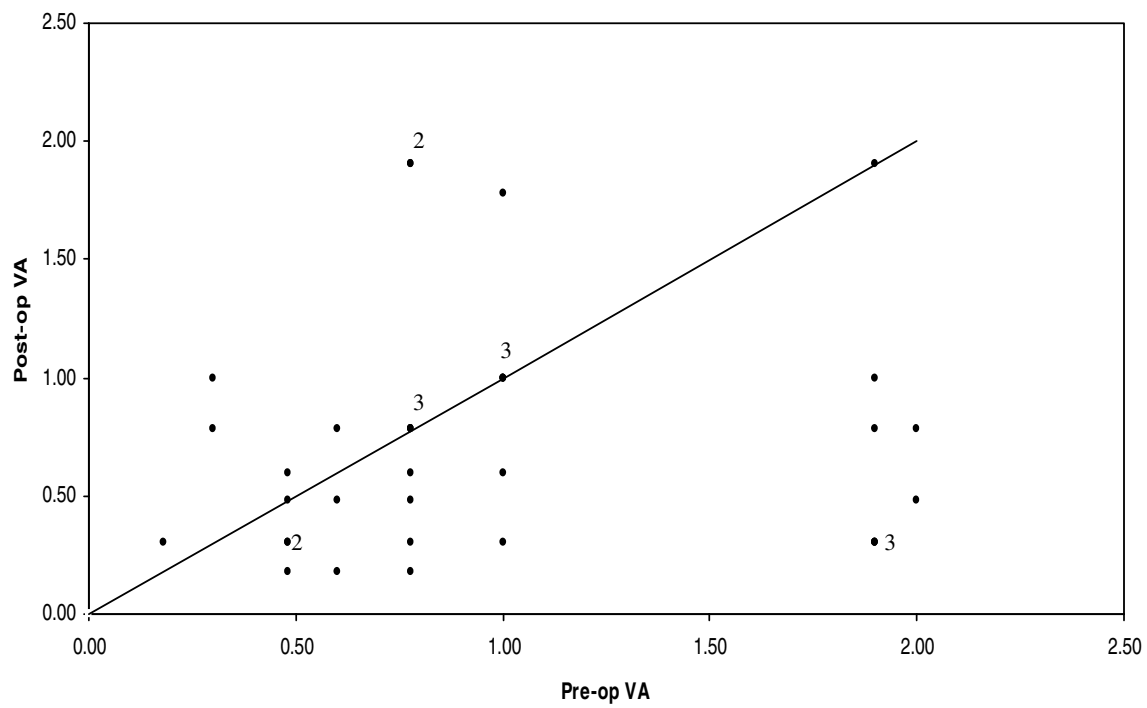

Figure 1 Non-ICG Logmar visual acuities pre- and postoperatively. Those cases represented below the diagonal line demonstrated an improvement in postoperative visual acuity.

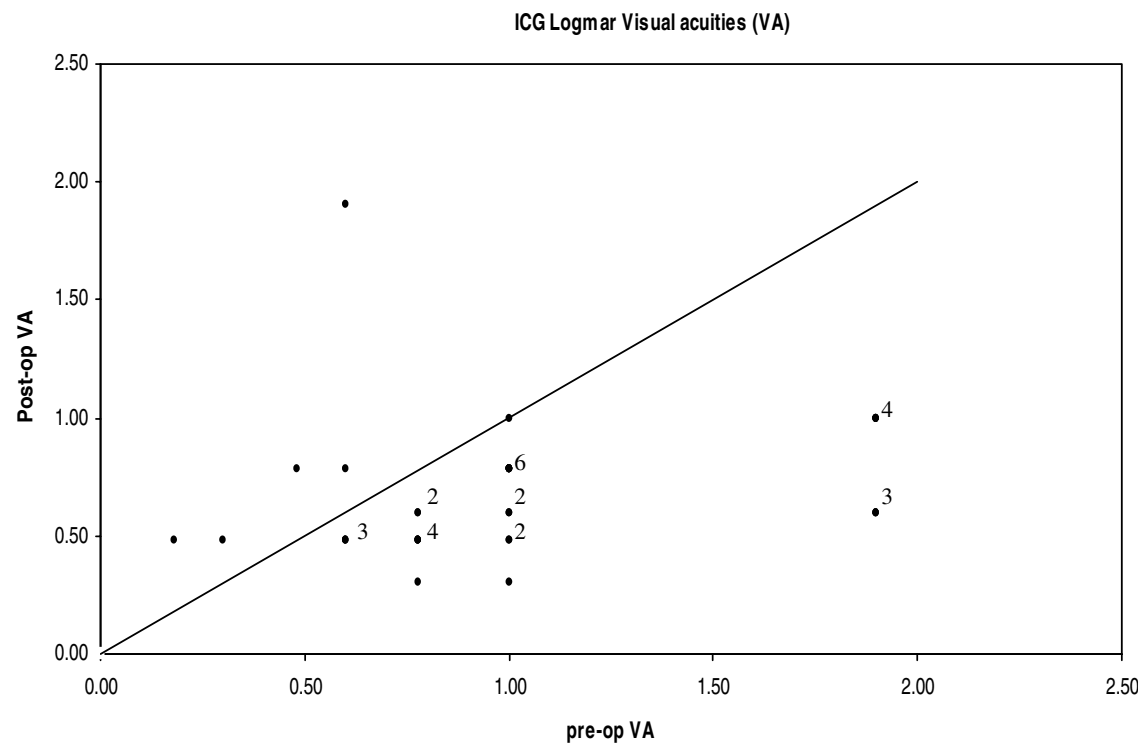

Figure 2 ICG Logmar visual acuities pre- and postoperatively. Those cases represented below the diagonal line demonstrated an improvement in postoperative visual acuity.

Table 2 Visual outcomes for 56 cases with successful primary hole closure

\begin{tabular}{lccc}
\hline & Non-ICG $(\mathrm{n}=25)$ & ICG $(\mathrm{n}=31)$ & P-value \\
\hline Preop Logmar & 0.99 & 1.00 & 0.93 \\
Final Logmar & $0.55(P<0.005)$ & $0.65(P<0.001)$ & 0.26 \\
Mean Logmar change & 0.45 & 0.38 & 0.64 \\
Snellen line change & 1.64 & 1.26 & 0.46 \\
$\geq 2$ lines of improvement & $13 / 25(52 \%)$ & $12 / 31(39 \%)$ & 0.32 \\
\hline
\end{tabular}

was 1.26 in the ICG group and 1.64 in the non-ICG group $(P=0.46)$. In the primary closure groups, if visual improvement is defined as a gain of $\geq 2$ lines of Snellen acuity then this was achieved by $39 \%$ of the ICG group compared with $52 \%$ of the non-ICG group. This difference failed to achieve significance $(P=0.32)$. 
Immediate postoperative complications included one retinal detachment, one iris prolapse, two vitreous haemorrhages, and five patients with transient elevated IOP. All these complications were treated successfully and without any adverse visual consequences. There were no episodes of late reopening of any macular holes.

\section{Discussion}

Macular holes can cause significant visual disability and visual loss. In all, $15 \%$ of patients develop a second macular hole in the opposite eye. ${ }^{15}$ Vitrectomy surgery has been shown to be effective in the closure of stage 2-4 macular holes. ${ }^{4,5}$ ILM contains myofibroblasts that contract and are thought to contribute to macular hole enlargement. ${ }^{16}$ Removal of the ILM around the hole has improved success in idiopathic hole closure. ${ }^{8}$

It is often difficult to assess completeness of the ILM peel. ICG stains ILM green, which contrasts with the underlying pink retina enabling the surgeon to ensure complete maculorhexis.

Differing closure rates are reported in the literature, depending on several factors such as the stage and duration of the macular hole and the use of ILM peeling. ${ }^{5,17}$ A prospective randomised controlled trial of 129 eyes reported anatomical closure in $69 \%$ of patients with just vitrectomy and gas tamponade. ${ }^{4}$ With additional ILM peeling, rates of closure have been reported at between 56 and $100 \% .^{6-11}$ With additional use of ICG-assisted ILM peeling, success rates of 87.8 and $88 \%$ have been reported. ${ }^{12,13}$ No published series of cases with ILM peeling, with or without ICG, has contained a control group. Our series, although retrospective, has attempted to provide control data. Our data suggest higher primary closure rates where ICG was used (91.2\%) compared to those cases where ICG was not used $(73.5 \%)$. This difference in closure rates approached statistical significance $(P=0.056)$.

There was a significant difference between the two groups amongst those patients achieving Logmar visual improvement above baseline: $53 \%$ in the non-ICG group compared to $82 \%$ in the ICG group $(P=0.01)$. This simply reflects, however, the higher closure rates in the ICG group. This study demonstrated no statistically significant difference in visual outcomes between the two groups where primary hole closure occurred.

Complications relating to ILM peeling include macular oedema, retinal pigment epithelial (RPE) changes, and small, mostly asymtomatic scotomas. ${ }^{18}$ Concerns have been expressed over possible RPE atrophy and poor visual outcomes linked to usage of ICG. ${ }^{19}$ Retinal pigment epitheliopathy is, however, a well-recognized complication of this surgery in the absence of ICG. ${ }^{18,20}$ Intraretinal accumulation of ICG has also been described and persistent staining observed, however, as yet there have been no conclusive reports of immediate or longterm ICG toxicity. ${ }^{21,22}$ In vitro experiments with brief exposure of cultured human retinal pigment epithelial cells to indocyanine green show decreased mitochondrial enzyme activity but without any changes to cell morphology or ultrastructure. ${ }^{23}$ A more recent study has suggested that human RPE cell exposure to ICG in the presence of acute illumination can illicit cell cycle arrest and apoptosis. A safety level of $0.25 \mathrm{mg} / \mathrm{ml}$ of ICG was recommended. ${ }^{24}$

In this study, the concentration used was $5 \mathrm{mg} / \mathrm{ml}$; however, based on these recent reports in the literature we now routinely use a concentration of $0.25-0.5 \mathrm{mg} / \mathrm{ml}$. Previous studies have used different concentrations of ICG, with varying exposure times and volumes. These include an unspecified volume of $5 \mathrm{mg} / \mathrm{ml} \mathrm{ICG}$ for 3$5 \mathrm{~min},{ }^{12}$ concentrations of $0.25,0.5$ and $1.25 \mathrm{mg} / \mathrm{ml}^{13}$ $1 \mathrm{mg} / \mathrm{ml}^{19}{ }^{19} 0.5 \mathrm{mg} / \mathrm{ml}$ for $1 \mathrm{~min},{ }^{22} 1 \mathrm{mg} / \mathrm{ml}$ for $20 \mathrm{~min}^{23}$ and $0.2-1.0 \mathrm{ml}$ of $5 \mathrm{mg} / \mathrm{ml} \mathrm{ICG}$ for an unspecified time. ${ }^{25}$

Other concerns have been raised about whether the underlying retina is damaged during the peel. It has been reported that ICG only stains the ILM and not the underlying retina, but a recent report on the histological findings in a case series of 10 patients showed that cleavage was not exactly below the ILM but may include inner retinal structures. ${ }^{25}$ However, successive attempts at peeling without staining can be equally adverse and time consuming. ${ }^{9}$ Other factors that may influence outcome are variations in the concentration, $\mathrm{pH}$, and contact time of ICG with the retina. ${ }^{25}$

A recent animal model has suggested toxic histological changes at intravitreal doses of ICG above $2.5 \mathrm{mg} / \mathrm{ml}$ and transient functional ERG changes recordable at lower doses. ${ }^{26}$ However, there was a prolonged exposure time of 2 weeks in this model.

ICG can provide a standardised approach with more easily recognised end points and reduced operating time. Our results show that ICG-assisted ILM peel was associated with higher closure rates following a single surgical procedure and overall higher rates of visual improvement. However, where primary hole closure occurred, the visual outcomes between the two groups were comparable.

\section{References}

1 Gass JD. Idiopathic senile macular hole. Its early stages and pathogenesis. Arch Ophthalmol 1998; 106: 629-639.

2 Gass JD. Reappraisal of biomicroscopic classification of stages of development of a macular hole. Am J Ophthalmol 1995; 19: 752-759. 
3 Kelly NE, Wendel RT. Vitreous surgery for idiopathic macular holes. Results of a pilot study. Arch Ophthalmol 1991; 09: 654-659.

4 Freeman WR, Azen SP, Kirn JW, el-Haing W, Mischell III DR, Bailey I. Vitrectomy for the treatment of full-thickness stage 3 or 4 macular holes. Results of a multicentre randomised controlled trial. The vitrectomy for treatment of Macular Hole Study Group. Arch Ophthalmol 1997; 15(1): 11-21.

5 Kim JW, Freeman WR, Azen SP, el-Haig W, Klein DJ, Bailey IL. Prospective randomized trial of vitrectomy or observation for stage 2 macular holes. Vitrectomy for Macular Hole Study Group. Am J Ophthalmol 1996; 121: 605614

6 Brooks Jr HL. Macular hole surgery with and without internal limiting membrane peeling. Ophthalmology 2000; 107, 193, 9-48

7 Park DW, Sipperley JO, Sneed SR, Dugel PU, Jacobsen J. Macular hole surgery with internal limiting membrane peeling and intravitreous air. Ophthalomogy 1999; 106(7): 1392-1397.

8 Mester V, Kuhn F. Internal limiting membrane removal in the management of full-thickness macular holes. Am J Ophthalmol 2000; 1(9): 769-777.

9 Smiddy WE, Feuer W, Cordahi G. Internal limiting membrane peeling in macular hole surgery. Ophthalmology 2001; 108: 1471-1478.

10 Haritoglou C, Gass CA, Schaumberger M, Gandorfer A, Ulbig MW, Kampik A. Long term follow up after macular hole surgery with ILM peeling. Am J Opthalmol 2002; 134(5): 661-666.

11 Ip MS, Baker BJ, Duker JS, Reichel E, Baumel CR, Gangon R et al. Anatomical outcomes of surgery for idiopathic macular holes determined by optical coherence tomography. Arch Ophthalmol 2002; 120: 29-35.

12 Da Mata AP, Burk SE, Riemann CD, Rosa Jr RH, Snyder ME, Petersen MR, Foster RE. Indocyanine green-assissted peeling of the retinal internal limiting membrane during vitrectomy surgery for macular hole repair. Ophthalmology 2001; 108(7): 1187-1192.

13 Kwok AKH, Lai TYY, Man-Chan W, Woo DCF. Indocyanin green assisted retinal internal limiting membrane removal in stage 3 or 4 macular hole surgery. Br J Ophthalmol 2003; 87: 71-74.

14 Tornambe PE, Poliner LS, Cohen RG. Definition of macular hole surgery end points: elevated/open, flat/open, flat/ closed. Retina 1998; 18: 286-287.
15 Ezra E, Wells JA, Gray RH, Kinsella FM, Orr GM, Grego J, Arden GB, Gregor ZJ. Incidence of idiopathic full-thickness macular holes in fellow eyes. A 5-year prospective natural history study. Ophthalmology 1998; 105(2): 353-359.

16 Yooh HS, Brooks Jr HL, Capone Jr A, L'Hernault NL, Grossniklaus HE. Ultrastructural features of tissue removed during idiopathic macular hole surgery. Am J Ophthalmol 1996; 122: 67-75.

17 Ryan EH, Gilbert HD. Results of surgical treatment of recent-onset full-thickness idiopathic macular holes. Arch Ophthalmol 1994; 112: 1545-1553.

18 Haritoglou C, Gass CA, Schaumberger M, Ehrt O, Gandorfer A, Kampik A. Macular changes after peeling of the internal limiting membrane in macular hole surgery. Am J Ohthalmol 2001; 132(3): 363-368.

19 Engelbrecht NE, Freeman J, Sternberg P, Aeberg Sr TM, Aeberg Jr TM, Martin DF et al. Retinal pigment epithelial changes after macular hole surgery with indocyanine greenassisted internal limiting membrane peeling. Am J Ophthalmol 2002; 133: 89-94.

20 Poliner LS, Tornambe PE. Retinal pigment epitheliopathy after macular hole surgery. Ophthalmology 1993; 100(11): 1604-1605.

21 Ho AC, Yannuzzi LA, Guyer DR. Intraretinal leakage of indocyanine green dye. Ophthalmology 1994; 101: 534-541.

22 Weinberger AW, Kirchhof B, Mazinani BE, Schrage NF. Persistent ICG fluorescence 6 weeks after intraocular ICG administration for macular hole surgery. Graefes Arch Clin Exp Ophthalmol 2001; 239(5): 388-390.

23 Sippy BD, Engelbracht NE, Hubbard GB, Moriarty SE, Jiang S, Aaberg Jr TM, Aaberg Sr TM, Grossniklaus HE, Stemberg Jr P. Indocyanine green effect on cultured human retinal pigment epithelial cell: implication for macular hole surgery. Am J Ophthalmol 2001; 132(3): 433-435.

24 Yam HF, Kwok AK, Chan KP, Lai TY, Chu KY, Lam DS, Pang CP. Effect of indocyanine green and illumination on gene expression in human pigment epithelial cells. Invest Ophthalmol Vis Sci 2003; 44(1): 370-377.

25 Gandorfer A, Hartioglou C, Gass CA. Indocyanine greenassissted peeling of the internal limiting membrane may cause retinal damage. Am J Ophthalmol 2001; 132(3): 431-432.

26 Enaida H, Sakamoto T, Hisatomi T, Goto Y, Ishibashi T. Morphological and functional damage of the retina caused by intravitreous indocyanine green in rat eyes. Graefes Arch Clin Exp Ophthalmol 2002; 240(3): 209-213. 